\title{
Another year of hard work through the Covid-19 pandemic
}

\author{
Quan- Hoang Vuong
}

October 24, 2021

OSF Preprint, doi: 10.31219/ osf.io/ cwav2

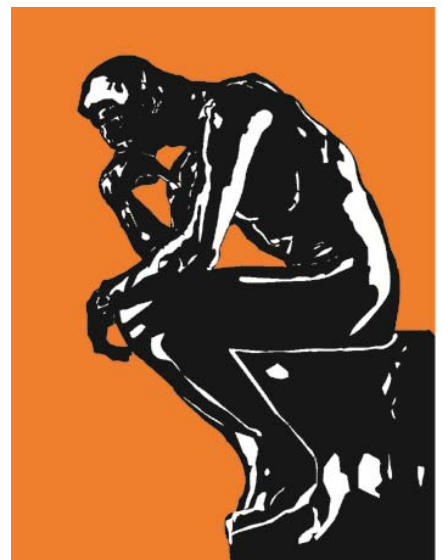

URL: https:// osf.io/ cwav2/

For our research endeavor, October might be regarded as the determining month of the year since we can already predict the whole year's outcome. And it is now the end of 2021 October.

Our research center has, thus far, undertaken all the challenges in the second Covid year with a strong determination for better results. It seems we have been able to do what we set out at the beginning of the year, thanks to the great efforts and focus of the whole team.

Nonetheless, the underlying modus operandi has an important role to play. For us, the modality benefits from past lessons learned from the early research period, when (seemingly unrelated) works like [1-2] were accomplished. The lessons have then been turned into the key principles that can later enable the team to function more efficiently and economically. It could have been more challenging for us to survive these unprecedented years had those principles not been institutionalized. And they are described in what follows.

The first principle deals with the issue of rational costs of doing research, as stipulated in [3]. Our team members agreed that the more we can achieve with the same amount of investment (or expenditure), the better off we can all become. One example of the benefit of implementing this principle during the 
year is our first replication study [4]. Although the earlier achievement has justified the costs and become an important part of the relevant literature [5], the replication study shows that aiming for the ultimate legitimacy and selfactualization does possess a practical philosophical value that a researcher should strive for.

The second principle [6] guides us through the difficulty of getting the works completed and published, an overwhelming task for this second year of Covid19. Each and every member has become proactive in identifying potential issues, not just about the quality of works but also the practicalities of the publishing activities.

There were times during 2021 when a study appeared to be accepted shortly before the publisher informed us that they failed to contact the handling editor, making the fate of our submission totally uncertain. We had little choice but to move on with new efforts to account for the potential loss. Applying [6] has led us to a disciplined action that requires us to double our effort to compensate for each possible loss.

Finally, the third one says that one should strictly abide by the "intellectual humility" value when undertaking one's scientific pursuit. The details of this important principle are given in [7]. Practicing this principle helps us mitigate the risks of:

i) doing the wrong things (or ineffective); and,

ii) doing things the wrong ways (or inefficient).

(And, naturally, one can see that by bringing about these benefits, the third principle can, in reality, reinforce the value of both the first and second principles as we have mentioned above.)

Personally, I tend to think that this third principle is a cousin to the "intellectual honesty" principle as described in George Polya's famous book How to Solve It [8]. It also resembles the analogy principle of [8] somehow.

Now, these principles are quite simple to appreciate, and none of them sounds intimidating. Nonetheless, practicing them requires tremendous patience and a strong discipline because most research programs take years to complete. A particular year's achievements may only reflect partial efforts of some other time in the past. Therefore, having survived the second Covid year has taught us other lessons on applying these principles more efficiently and creatively.

To conclude, the results so far have given us some confidence that will likely make our third Covid year (i.e., 2022) a little less dreadful. 


\section{References}

[1] Van Huu, N., Hoang, V. Q., \& Ngoc, T. M. (2005) Central limit theorem for functional of jump Markov processes. Vietnam Journal of Mathematics, 33(4), 443- 461.

[2] Van Huu, N., \& Hoang, V. Q. (2007) On the martingale representation theorem and on approximate hedging a contingent claim in the minimum deviation square criterion. In: R. Jeltsch, T-T. Li \& I. H. Sloan (Eds.) Some Topics in Industrial and Applied Mathematics (pp. 134- 151). Hackensack, New Jersey: World Scientific.

[3] Vuong, Q. H. (2018). The (ir) rational consideration of the cost of science in transition economies. Nature Human Behaviour, 2(1), 5- 5.

[4] Vuong, Q. H., La, V. P., Nguyen, M. H., Nguyen, T. H. T., \& Ho, M. T. (2021). Good budget or good care: The dilemma of social health insurance in Vietnam. SAGE Open Medicine, 9, 20503121211042512.

[5] Vuong, Q. H. (2015). Be rich or don't be sick: estimating Vietnamese patients' risk of falling into destitution. SpringerPlus, 4, 529.

[6] Vuong, Q. H. (2019). Breaking barriers in publishing demands a proactive attitude. Nature Human Behaviour, 3(10), 1034- 1034.

[7] Vuong, Q. H. (2020). Reform retractions to make them more transparent. Nature, 582(7811), 149- 149.

[8] Polya, G. (2004). How to Solve It: A New Aspect of Mathematical Method. Princeton University Press. 